\title{
Ultrasonic enhancement of drug penetration in solid tumors
}

\section{Chun-Yen Lai ${ }^{\dagger}$, Brett Z. Fite ${ }^{\dagger}$ and Katherine W. Ferrara*}

Department of Biomedical Engineering, University of California Davis, Davis, CA, USA

Edited by:

Ronald Berenson, Compliment

Corporation, USA

\section{Reviewed by:}

Hervé Emonard, Centre National de la

Recherche Scientifique, France

Jacques Barbet, Arronax GIP, France

\section{${ }^{*}$ Correspondence:}

Katherine W. Ferrara, Department of

Biomedical Engineering, University of

California Davis, 451 East Health

Sciences Drive, Davis, CA 95616,

USA

e-mail: kwferrara@ucdavis.edu

${ }^{\dagger}$ Chun-Yen Lai and Brett Z. Fite have

contributed equally to this work.
Increasing the penetration of drugs within solid tumors can be accomplished through multiple ultrasound-mediated mechanisms. The application of ultrasound can directly change the structure or physiology of tissues or can induce changes in a drug or vehicle in order to enhance delivery and efficacy. With each ultrasonic pulse, a fraction of the energy in the propagating wave is absorbed by tissue and results in local heating. When ultrasound is applied to achieve mild hyperthermia, the thermal effects are associated with an increase in perfusion or the release of a drug from a temperature-sensitive vehicle. Higher ultrasound intensities locally ablate tissue and result in increased drug accumulation surrounding the ablated region of interest. Further, the mechanical displacement induced by the ultrasound pulse can result in the nucleation, growth and collapse of gas bubbles. As a result of such cavitation, the permeability of a vessel wall or cell membrane can be increased. Finally, the radiation pressure of the propagating pulse can translate particles or tissues. In this perspective, we will review recent progress in ultrasound-mediated tumor delivery and the opportunities for clinical translation.

\section{THE PROBLEM}

The goal of this Frontiers issue is to explore methods to enhance the penetration of drugs within solid tumors. Combining ultrasound with a drug does indeed have the potential to enhance delivery; however, due to the requirement to guide the beam to the tumor such treatment will be a possibility only for localized primary tumors and well-characterized metastases that are accessible to sound waves. Ultrasound is easily directed to superficial organs such as the breast and prostate, as well as most abdominal organs, and has also been applied in the treatment of brain tumors. The effects of high intensity ultrasound on biological tissue, and particularly on the central nervous system, have been recognized for more than 70 years; the ability to heat and ablate tissue was described initially $(1-5)$. Within studies in the 1940s and 1950s, ultrasound was also determined to have non-thermal effects on tissue, typically characterized as mechanical effects (6). The mechanical effects of ultrasound can act directly upon the tumor tissue or on injected microbubbles whose oscillations enhance vascular or cell membrane permeability. Although early studies were not geared toward drug delivery, these same mechanisms of high temperature ablation or mild hyperthermia can increase drug accumulation within a lesion and lesion boundary. In recent strategies, the increased temperature is applied to influence both the tissue and the drug capsule.

\section{ENHANCED EXTRAVASATION OF NANOTHERAPEUTICS THROUGH MECHANICAL AND THERMAL EFFECTS ON TISSUE The direct effects of ultrasound on tissue and vasculature have been reported to enhance the extravasation of antibodies and nanotherapeutics (7-9). In some cases, the mechanical effects of ultrasound have been shown to enhance therapeutic penetration.}

With a center frequency of $1 \mathrm{MHz}$ ultrasound at a peak negative pressure (PNP) of $8.95 \mathrm{MPa}$, antibody penetration has been shown to be enhanced at the tumor periphery, presumably through mechanical effects (8). The compression and rarefaction resulting from the ultrasound wave can produce the nucleation, growth, and collapse of gas bubbles within tissues. Such cavitation is assumed to facilitate transport within tumor tissue.

The thermal dose delivered by ultrasound is typically measured in cumulative equivalent minutes at $43^{\circ} \mathrm{C}$ (CEM 43) which is defined as $t R^{(43-T)}$, with $t$ being the time of treatment, $T$ the average temperature during treatment, and $R$ a constant that equals 0.25 for temperatures between 37 and $43^{\circ} \mathrm{C}$ and 0.5 above $43^{\circ} \mathrm{C}(10,11)$. Hyperthermia has been demonstrated to increase tumor blood flow and microvascular permeability (12). While it has long been recognized that heat increases the accumulation of small particles in the heated region of interest, the typical protocol has involved $1 \mathrm{~h}$ or more of heating. However, by combining the mechanical and thermal effects of ultrasound, enhanced delivery has been achieved with a shorter treatment (13). In such studies, the temperature goal is $\sim 41-42^{\circ} \mathrm{C}$ and insonation continued for $\sim 5-20 \mathrm{~min}$. As a result of hyperthermia and the mechanical effects of ultrasound, we have observed that the accumulation of liposomes in an insonified tumor can be increased up to threefold to as much as $22 \% \mathrm{ID} / \mathrm{g}$. While ultrasound was shown to enhance accumulation in syngeneic murine tumors, the ultrasound parameters that were required to enhance nanoparticle accumulation were shown to differ between epithelial and epithelial-mesenchymal transition (EMT) tumor phenotypes (7). While mild hyperthermia enhanced accumulation in the epithelial tumors, likely through decreased intratumoral pressure and enhanced apparent permeability, higher ultrasound pressure was 
required to enhance delivery in the poorly vascularized EMT phenotype. Further, excessive temperature or thermal dose can result in vascular stasis, particularly in highly vascular epithelial tumors. The requirement to personalize the ultrasound parameters to the tumor biology will likely require image guidance to insure clinical success.

In part due to the differing effects of mild hyperthermia with tumor biology, the use of high temperature ablation to enhance delivery has been explored as a methodology that is likely to be generally effective in increasing delivery. While it seems counterintuitive that tissue ablation can greatly enhance accumulation, edema, enhanced blood flow, and increased transport in the region surrounding the ablated site can successfully improve delivery. In our experience, the peak delivery in regions surrounding ablation can exceed $30 \% \mathrm{ID} / \mathrm{g}$. Also of clinical interest, the hyperthermia surrounding radiofrequency (rf) ablation lesions has been used to enhance local delivery; however, the temperature obtained with such devices ranges from 50 to $90^{\circ} \mathrm{C}(14)$. Rf ablation has been applied in previous studies to achieve a similar enhanced delivery, and such techniques are now in clinical trials $(15,16)$. High intensity focused ultrasound similarly enhances delivery surrounding the site of ablation, although combinations of ablation and drug delivery remain primarily under pre-clinical investigation.

\section{RELEASE OF DRUG FROM NANOPARTICLES WITHIN THE VASCULATURE}

Nanoparticles that can be triggered to release a small molecule cargo within a tumor have shown the potential to increase both the local concentration of the drug and tumor penetration. Yet, the challenge of developing particles that are stable in circulation and release their cargo upon activation has long been recognized as a major challenge in pharmaceutical development. While many activatable particles are under development (11, 17-23), thermally sensitive liposomes have been frequently combined with ultrasound in recent pre-clinical and clinical studies and will be considered here. In studies of thermally sensitive liposomes, imaging has been used to verify that amphipathic cargo released within the tumor vasculature remains concentrated within the tumor in the region of release (18). We have found that release of drug from such temperature-sensitive vehicles can be highly effective, resulting in a complete response in aggressive murine tumors (unpublished data).

Temperature-sensitive liposomes were initially proposed containing 1,2-dipalmitoyl-sn-glycero-3-phosphocholine (DPPC) with a phase transition of $T_{\mathrm{m}}=\sim 41^{\circ} \mathrm{C}$ and multiple formulations containing DPPC have been proposed $(24,25)$. The incorporation of lyso-phospholipids in DPPC-based liposomes decreases the phase transition temperature and speeds the release of the cargo, likely due to the creation of local defects within the lipid bilayer (26). The Thermodox ${ }^{\mathrm{TM}}$ formulation, with the incorporation of a lyso-phospholipid, releases at a clinically desirable temperature of $\sim 39^{\circ} \mathrm{C}$. The incorporation of the lyso-phospholipids also enhances the ion permeability and drug release rates at the membrane phase transition (27). Unfortunately, using the conventional ammonium sulfate loading, liposomes containing lysophospholipids also rapidly release their cargo within the blood pool. As a result, while local delivery can be achieved within tens of minutes after injection, the dose limiting toxicities of such formulations have typically limited their application to single dose administration. Although the pre-clinical data using Thermodox has been very exciting, this activatable doxorubicin formulation reportedly failed to meet its primary endpoint in the Phase III HEAT Study in patients with hepatocellular carcinoma (HCC). Yet, in spite of this setback, the potential for temperature-sensitive vehicles to have a significant impact on the concentration and penetration of drugs within solid tumors is substantial. Although early clinical studies have typically been limited to one-time treatment, with new formulations repeated treatment should be feasible and the resulting clinical impact enhanced. Multiple alternative formulations have been proposed and compared and have been shown to enhance circulation time $(25,28-30)$. Alternative strategies using metal-drug complexes, a Brij surfactant and phosphatidylglycerol have been reported to enhance the stability of temperature-sensitive liposomes and are promising alternatives for future investigation. The ultrasound parameters used to enhance delivery with temperature-sensitive liposomes have also varied widely with the center frequency typically ranging from 1 to $3 \mathrm{MHz}$ and duty cycle ranging from $\sim 10$ to $100 \%(20,31,32)$.

\section{MICROBUBBLES}

Micron-scale gas bubbles with a stabilizing shell are used in ultrasound imaging to improve imaging of the blood pool and have been widely applied in pre-clinical studies of enhanced drug delivery. The microbubble shell can be coupled to nanotherapeutics, such as liposomes, or coated with a drug $(33,34)$. The gas core can transport oxygen or other useful gas cargo, although for imaging the gas core is selected to reduce diffusion through the shell material (35). Alternative formulations in which liquid perfluorocarbon particles are injected and change to a gaseous phase in vivo have also been shown to have efficacy in the delivery of drugs to solid tumors (36).

Reflections of ultrasound waves from tissue increase in proportion to variations in density and compressibility of the medium and therefore highly compressible gas bubbles produce strong ultrasound echoes. These small bubbles expand and contract in response to ultrasound waves. When driven at a frequency near the resonance frequency that is determined by the size and physical composition of the microbubble, a multi-fold expansion can result. During the subsequent collapse, the velocity of the microbubble wall can reach hundreds of meters per second $(37,38)$, and the gas core can fragment into a set of small gas particles (39). Also, during microbubble collapse, small jets can impact nearby cell membranes and result in enhanced transport of materials into the cell. In vitro studies in phantom materials and ex vivo studies within tissues have confirmed that the oscillating microbubble can travel through the vessel wall or can affect the mechanical integrity of the vessel (40-42). Still, such jets affect cells only within a distance on the order of tens of microns. Therefore, the application of microbubbles to alter vascular, rather than tumor cell, permeability is attractive since the vascular concentration is initially high and large numbers of microbubbles are required to effectively change the membrane permeability of a large fraction of cells within a tissue. Within the vasculature, catheters have also been applied to direct streams of bubbles to a 
region of interest (43). Also, microbubble-enhanced gene delivery has been widely studied since the biological amplification resulting from transfection is expected to increase the impact of treatment although the protocols have varied (44-48). Within such studies, microbubbles and DNA have been co-injected or combined into a single vehicle and the administration has been intratumoral or intravascular. Typical ultrasound parameters for enhanced tumor gene delivery have included a center frequency on the order of $1 \mathrm{MHz}$ and a low pulse repetition frequency; however, the peak negative ultrasound pressure has varied significantly and successful transfection at higher ultrasound frequencies has also been reported.

The ultrasound parameters used to increase vascular permeability must be chosen carefully as insonation of microbubbles with low ultrasound frequencies has been shown to reduce blood flow (49). A parameter space for safe and effective use of microbubbles for enhancing vascular permeability has been established (41, 50-52). Many parameters, including microbubble dosage and size, the ultrasound center frequency, pulse duration, pulse repetition frequency, and the PNP determine the effect of the oscillating microbubble on the surrounding tissue.

In addition to the formation of jets, physical mechanisms exploited in microbubble-enhanced delivery include radiation forces and microstreaming of fluid $(53,54)$. Radiation force refers to a mechanism by which oscillating microbubbles or other particles are displaced, most typically in the direction of wave propagation (55-57). This displacement can be used to enhance vascular targeting of a microbubble or microbubble-drug conjugate. Further, local motion of fluid surrounding the oscillating bubble is known as microstreaming and has been shown to increase cellular uptake of therapeutics $(53,54)$.

One of the most important applications for the use of microbubbles to enhance delivery has been the enhancement of blood brain barrier (BBB) permeability (58-65). In general, the technique consists of systemically injecting microbubbles and insonifying the region of the brain where enhanced permeability is desired. Here again, a parameter space has been established within which enhanced BBB transport is achieved with minimal hemorrhage and cell death. Still, the extension of these techniques into the clinic is expected to require the use of real-time cavitation detection, as individual variations in the skull penetration of the ultrasound wave are significant and the therapeutic window for effective and safe therapy is relatively small (66). As noted above, pre-clinical-application of microbubble-enhanced delivery is widespread. In addition, the authors are aware of yet unreported small clinical studies of microbubble-enhanced delivery to solid tumors.

\section{APPLICATION OF IMAGING TECHNOLOGY}

A major reason for the expansion of the application of therapeutic ultrasound is the development of methods to monitor the treated location and the temperature using MRI (67) or ultrasound (68). While mild hyperthermia (CEM $43<0.5$ ) is associated with increased metabolism, blood flow, and tissue repair, higher thermal doses are associated with enhanced cell death and therefore the methods to carefully control and monitor the delivered temperature are critically important (69). Image guidance using nuclear medicine techniques is also attractive due to their high sensitivity and the opportunity for quantitation of delivery $(70,71)$. By radiolabeling nanoparticles, the rate and magnitude of extravasation can be directly estimated from PET data (71). Even with the relatively low spatial resolution of PET $(\sim 1 \mathrm{~mm})$, the penetration of nanoparticle-based therapeutics has been assessed and shown to differ from small molecular weight agents (72).

In order to fully evaluate the enhanced penetration of a drug resulting from ultrasound, multiple imaging labels can be incorporated with drug accumulation and penetration assessed at the whole body, organ, and cellular scales $(8,9,70,73,74)$. Multiple MRI protocols can be proposed for the guidance of ultrasound therapies including diffusion-weighted $(75,76), \mathrm{T} 2$-weighted $(77$, 78), and contrast enhanced T1-weighted imaging (79-81), fluid attenuated inversion recovery (FLAIR) (82), heteronuclear $\left({ }^{23} \mathrm{Na}\right)$ (83), spectroscopy (84), and displacement sensitive sequences via MR elastography (85). Following HIFU ablation of the prostate, gadolinium enhanced MRI is often used to evaluate the extent of tissue damage. Although contrast enhanced T1-weighted MRI can detect tissue damage following HIFU ablation $(86,87)$, it does not correlate to histological results (intensity of necrosis, presence of foci of viable cancer) immediately following HIFU (87). However, for follow-up examinations, DCE MRI has demonstrated good sensitivity and diffusion MRI has shown specificity in identifying tumor progression after HIFU ablation $(75,88)$.

In addition to endogenous contrast mechanisms that can be used to guide and assess ultrasound therapies, exogenous agents can be used to report on specific changes. For example, coadministration of two paramagnetic contrast agents (gadolinium and thulium) within liposomal drug carriers has been previously utilized to follow internalization and cellular trafficking of the vehicle (89). Similarly, multi modal liposomal agents spanning CT and MRI have been used to assess the penetration of liposomes within tumors and have been proposed for cross modality registration and as a means to guide imaging-based interventions $(73,74)$. Many physiological parameters can also be assessed by MRI and coupled with the soft tissue anatomical information motivate MRI as an excellent tool for guiding thermal therapies $(90,91)$.

In addition to the role of MRI in the assessment of drug penetration and distribution, MR thermometry can be applied to monitor the temperature of a region during an intervention (92-100). The proton resonance frequency (PRF) of water is frequently used to detect changes in temperature (101) both because it has a thermal coefficient that is linear over a wide temperature range and, excepting adipose tissue, the PRF shift has little dependence on tissue type even following coagulation $(99,102)$. The PRF shift can be measured rapidly with gradient echo sequences, which is advantageous during thermal therapies where high temporal resolution is desirable, especially during ablative processes, to avoid damage to surrounding tissue. Further increases in temporal resolution can be gained via partial parallel imaging techniques using phased arrays (103-105) utilizing various algorithms (105).

Neither clinical focused ultrasound (FUS) systems, which typically operate around $1 \mathrm{MHz}(106,107)$, nor clinical MR scanners (e.g., 1.5, or $3 \mathrm{~T}$ ) are ideal for small animal imaging. In the former, 
the focal spot depth may encompass an appreciable portion of the animal, while the latter may have insufficient signal-to-noise ratio (SNR) to easily obtain detailed images of murine tumors. The smaller focal depth at higher FUS frequencies makes them more suitable for pre-clinical imaging of small animals (108). High field scanners are especially useful for small animal thermal imaging because in addition to providing higher SNR, which can be used for higher spatial resolutions, they also improve the sensitivity of thermal measurements made with the PRF shift method, which itself has a first order dependence on magnetic field strength.

\section{FUTURE APPLICATIONS}

The use of the thermal and mechanical effects of ultrasound to enhance delivery to solid tumors is expanding. With the increasing availability of MRI-guided high intensity focused ultrasound, well-controlled and calibrated clinical studies are feasible. Both the use of ultrasound to alter tissue properties and to release a drug from a carrier are in widespread pre-clinical evaluation. With the addition of microbubbles, drug penetration through the endothelium can also be increased, although the protocols are currently more complex due to the need to co-inject the therapeutic and microbubbles.

\section{REFERENCES}

1. Wall PD, Fry WJ, Stephens R, Tucker D, Lettvin JY. Changes produced in the central nervous system by ultrasound. Science (1951) 114:686-7. doi:10. 1126/science.114.2974.686

2. Fry WJ, Dunn F. Ultrasonic irradiation of the central nervous system at high sound levels. J Acoust Soc Am (1956) 28:129-31. doi:10. $1121 / 1.1908200$

3. Fry FJ, Ades HW, Fry WJ. Production of reversible changes in the central nervous system by ultrasound. Science (1958) 127:83-4. doi:10.1126/science. 127.3289.83

4. Lynn JG, Zwemer RL, Chick AJ, Miller AE. A new method for the generation and use of focused ultrasound in experimental biology. J Gen Physiol (1942) 26:17993. doi:10.1085/jgp.26.2.179

5. Lynn J, Zwemer RL, Chick AJ. The biological application of focused ultrasound waves. Science (1942) 96:119-20. doi:10. 1126/science.96.2483.119

6. Fry WJ, Wulff VJ, Tucker D, Fry FJ. Physical factors involved in ultrasonically induced changes in living systems: Identification of non-temperature effects. $J$ Acoust Soc Am (1950) 22:867-76. doi:10. 1121/1.1906707

7. Watson K, Lai CY, Qin S, Kruse DE, Lin YC, Seo JW, et al. Ultrasound increases nanoparticle delivery by reducing intratumoral pressure and increasing transport in epithelial and epithelial-mesenchymal transition tumors. Cancer Res (2012) 72:1485-93. doi:10.1158/ 0008-5472.CAN-11-3232

8. Wang S, Shin IS, Hancock H, Jang B-S, Kim H-S, Lee SM, et al. Pulsed high intensity focused ultrasound increases penetration and therapeutic efficacy of monoclonal antibodies in murine xenograft tumors. J Control Release (2012) 162:218-24. doi:10.1016/j.jconrel. 2012.06.025

9. Frenkel V. Ultrasound mediated delivery of drugs and genes to solid tumors. Adv Drug Deliv Rev (2008) 60:1193-208. doi:10.1016/ j.addr.2008.03.007

10. Dewhirst MW, Vujaskovic Z, Jones E, Thrall D. Re-setting the biologic rationale for thermal therapy. Int J Hyperthermia (2005) 21:779-90. doi:10.1080/02656730500271668

11. Jones EL, Oleson JR, Prosnitz LR, Samulski TV, Vujaskovic Z, Yu $\mathrm{DH}$, et al. Randomized trial of hyperthermia and radiation for superficial tumors. J Clin Oncol (2005) 23:3079-85. doi:10.1200/ JCO.2005.05.520

12. Gaber MH, Wu NZ, Hong K, Huang SK, Dewhirst MW, Papahadjopoulos D. Thermosensitive liposomes: extravasation and release of contents in tumor microvascular networks. Int $J$ Radiat Oncol Biol Phys (1996) 36:1177-87. doi:10.1016/S03603016(96)00389-6

In the future, the effects of ultrasound may transcend the local effect through enhanced immune response. The addition of immunotherapy to standard-of-care cancer therapies has shown evidence of efficacy in the pre-clinical and clinical settings (109115 ). The immune system is often tolerant to antigens presented by the tumor and therefore strategies to induce tumor-specific immunity must overcome obstacles including: insufficient and dysfunctional populations of antigen-presenting cells and lymphocytes, the difficulty of inducing potent immunity without inducing unacceptable autoimmune toxicities, the low immunogenicity of antigens expressed by tumor cells, and immunoregulatory pathways that dampen the tumor-specific immune response (116). The use of ultrasound ablation to generate an immune response has been shown to be a promising technique for immune activation (110-112, 114, 115, 117-121). Ultrasound ablation is thought to act through dendritic cell maturation and T-cell immunity (122), and is particularly advantageous because it is completely noninvasive, can be controlled with high spatial precision and uses no harmful ionizing radiation $(123,124)$.

\section{ACKNOWLEDGMENTS}

The authors acknowledge the support of NIHCA103828, NIHCA134659 and NIHCA112356

13. Yuh EL, Shulman SG, Mehta SA Xie J, Chen L, Frenkel V, et al. Delivery of systemic chemotherapeutic agent to tumors by using focused ultrasound: study in a murine model. Radiology (2005) 234(2):431-7. doi:10.1148/radiol. 2342030889

14. Ahmed M, Monsky WE, Girnun G, Lukyanov A, D'Ippolito G, Kruskal JB, et al. Radiofrequency thermal ablation sharply increases intratumoral liposomal doxorubicin accumulation and tumor coagulation. Cancer Res (2003) 63:632733.

15. Goldberg SN, Ahmed M. Minimally invasive image-guided therapies for hepatocellular carcinoma. J Clin Gastroenterol (2002) 35:S115-29. doi:10.1097/ 00004836-200211002-00008

16. Wood BJ, Poon RT, Locklin JK, Dreher MR, Ng KK, Eugeni $M$, et al. Phase I study of heat-deployed liposomal doxorubicin during radiofrequency ablation for hepatic malignancies. J Vasc Interv Radiol (2012) 23: 248-55. doi:10.1016/j.jvir.2011.10. 018

17. Viglianti BL, Abraham SA, Michelich CR, Yarmolenko PS, MacFall JR, Bally MB, et al. In vivo monitoring of tissue pharmacokinetics of liposome/drug using MRI: illustration of targeted delivery. Magn Reson Med (2004) 51:1153-62. doi:10.1002/mrm. 20074
18. Ponce AM, Viglianti BL, Yu DH, Yarmolenko PS, Michelich CR, Woo J, et al. Magnetic resonance imaging of temperaturesensitive liposome release: drug dose painting and antitumor effects. J Natl Cancer Inst (2007) 99:53-63. doi:10.1093/jnci/ djk005

19. Kong G, Anyarambhatla G, Petros WP, Braun RD, Colvin OM, Needham D, et al. Efficacy of liposomes and hyperthermia in a human tumor xenograft model: importance of triggered drug release. Cancer Res (2000) 60:6950-7.

20. Dromi S, Frenkel V, Luk A, Traughber B, Angstadt M, Bur $M$, et al. Pulsed-high intensity focused ultrasound and low temperature sensitive liposomes for enhanced targeted drug delivery and antitumor effect. Clin Cancer Res (2007) 13:2722-7. doi:10.1158/1078-0432.CCR-062443

21. Loo C, Lowery A, Halas N, West J, Drezek R. Immunotargeted nanoshells for integrated cancer imaging and therapy. Nano Lett (2005) 5:709-11. doi:10.1021/ nl050127s

22. Derfus AM, von Maltzahn G, Harris TJ, Duza T, Vecchio KS, Ruoslahti E, et al. Remotely triggered release from magnetic nanoparticles. Adv Mater (2007) 19:3932-6. doi:10.1002/adma.200700091 
23. Gannon CJ, Patra CR, Bhattacharya R, Mukherjee $\mathrm{P}$, Curley SA. Intracellular gold nanoparticles enhance noninvasive radiofrequency thermal destruction of human gastrointestinal cancer cells. J Nanobiotechnol (2008) 6:2. doi:10.1186/1477-3155-6-2

24. Yatvin MB, Weinstein JN, Dennis WH, Blumenthal R. Design of liposomes for enhanced local release of drugs by hyperthermia. Science (1978) 202:1290-3. doi:10.1126/ science.364652

25. Paoli EE, Kruse DE, Seo JW, Zhang $\mathrm{H}$, Kheirolomoom A, Watson KD, et al. An optical and microPET assessment of thermally-sensitive liposome biodistribution in the Met-1 tumor model: Importance of formulation. J Control Release (2010) 143:13-22. doi:10.1016/j. jconrel.2009.12.010

26. Needham D, Anyarambhatla G, Kong G, Dewhirst MW. A new temperature-sensitive liposome for use with mild hyperthermia: characterization and testing in a human tumor xenograft model. Cancer Res (2000) 60:1197-201.

27. Mills JK, Needham D. Lysolipid incorporation in dipalmitoylphosphatidylcholine bilayer membranes enhances the ion permeability and drug release rates at the membrane phase transition. Biochim Biophys Acta (2005) 1716:77-96. doi:10.1016/j. bbamem.2005.08.007

28. Tagami T, Ernsting MJ, Li SD. Optimization of a novel and improved thermosensitive liposome formulated with DPPC and a Brij surfactant using a robust in vitro system. J Control Release (2011) 154:290-7. doi:10.1016/j. jconrel.2011.05.020

29. Lindner LH, Eichhorn ME, Eibl $H$, Teichert N, Schmitt-Sody M, Issels RD, et al. Novel temperaturesensitive liposomes with prolonged circulation time. Clin Cancer Res (2004) 10:2168-78. doi:10. 1158/1078-0432.CCR-03-0035

30. Kheirolomoom A, Mahakian LM, Lai C-Y, Lindfors HA, Seo JW, Paoli EE, et al. Copper-doxorubicin as a nanoparticle cargo retains efficacy with minimal toxicity. Mol Pharm (2010) 7:1948-58. doi:10. 1021/mp100245u

31. Partanen A, Yarmolenko PS, Viitala A, Appanaboyina S, Haemmerich D, Ranjan A, et al. Mild hyperthermia with magnetic resonanceguided high-intensity focused ultrasound for applications in drug delivery. Int J Hyperthermia (2012) 28:320-36. doi:10.3109/ 02656736.2012 .680173

32. Staruch RM, Ganguly M, Tannock IF, Hynynen K, Chopra R. Enhanced drug delivery in rabbit VX2 tumours using thermosensitive liposomes and MRIcontrolled focused ultrasound hyperthermia. Int J Hyperthermia (2012) 28:776-87. doi:10.3109/ 02656736.2012.736670

33. Lum AFH, Borden MA, Dayton PA, Kruse DE, Simon SI, Ferrara KW. Ultrasound radiation force enables targeted deposition of model drug carriers loaded on microbubbles. J Control Release (2006) 111:12834. doi:10.1016/j.jconrel.2005.11. 006

34. Kheirolomoom A, Dayton PA, Lum AFH, Little E, Paoli EE, Zheng $\mathrm{H}$, et al. Acoustically-active microbubbles conjugated to liposomes: characterization of a proposed drug delivery vehicle. J Control Release (2007) 118: 275-84. doi:10.1016/j.jconrel. 2006.12.015

35. Kwan JJ, Kaya M, Borden MA, Dayton PA. Theranostic oxygen delivery using ultrasound and microbubbles. Theranostics (2012) 2:1174-84. doi:10.7150/thno.4410

36. Rapoport N. Phase-shift, stimuliresponsive perfluorocarbon nanodroplets for drug delivery to cancer. Wiley Interdiscip Rev Nanomed Nanobiotechnol (2012) 4:492-510. doi:10.1002/wnan.1176

37. Chomas JE, Dayton PA, May D, Allen J, Klibanov A, Ferrara K Optical observation of contrast agent destruction. Appl Phys Lett (2000) 77:1056-8. doi:10.1063/1. 1287519

38. Chomas JE, Dayton P, May D, Ferrara K. Threshold of fragmentation for ultrasonic contrast agents. J Biomed Opt (2001) 6:141-50. doi:10.1117/1.1352752

39. Chomas JE, Dayton P, Allen J, Morgan K, Ferrara KW. Mechanisms of contrast agent destruction. IEEE Trans Ultrason Ferroelectr Freq Control (2001) 48:23248. doi:10.1109/58.896136

40. Qin S, Caskey CF, Ferrara KW. Ultrasound contrast microbubbles in imaging and therapy: physical principles and engineering. Phys Med Biol (2009) 54:R27-57. doi: 10.1088/0031-9155/54/6/R01

41. Caskey CF, Stieger SM, Qin S, Dayton PA, Ferrara KW. Direct observations of ultrasound microbubble contrast agent interaction with the microvessel wall. J Acoust Soc Am (2007) 122:1191-200. doi:10. 1121/1.2747204

42. Caskey CF, Qin S, Dayton PA, Ferrara KW. Microbubble tunneling in gel phantoms. J Acoust Soc Am (2009) 125:EL183-9. doi:10.1121/ 1.3097679

43. Kilroy JP, Klibanov AL, Wamhoff BR, Hossack JA. Intravascular ultrasound catheter to enhance microbubble-based drug delivery via acoustic radiation force. IEEE Trans Ultrason Ferroelectr Freq Control (2012) 59:2156-66. doi:10. 1109/TUFFC.2012.2442

44. Miller DL, Song J. Lithotripter shock waves with cavitation nucleation agents produce tumor growth reduction and gene transfer in vivo. Ultrasound Med Biol (2002) 28:1343-8. doi:10.1016/ S0301-5629(02)00572-0

45. Miller DL, Song J. Tumor growth reduction and DNA transfer by cavitation-enhanced highintensity focused ultrasound in vivo. Ultrasound Med Biol (2003) 29:887-93. doi:10.1016/ S0301-5629(03)00031-0

46. Hauff P, Seemann S, Reszka R, Schultze-Mosgau M, Reinhardt M, Buzasi T, et al. Evaluation of gas-filled microparticles and sonoporation as gene delivery system: feasibility study in rodent tumor models. Radiology (2005) 236:572-8. doi:10. 1148/radiol.2362040870

47. Howard CM, Forsberg F, Minimo C, Liu JB, Merton DA, Claudio PP. Ultrasound guided site specific gene delivery system using adenoviral vectors and commercial ultrasound contrast agents. J Cell Physiol (2006) 209:413-21. doi:10. 1002/jcp. 20736

48. Sonoda S, Tachibana K, Uchino E, Yamashita T, Sakoda K, Sonoda $\mathrm{KH}$, et al. Inhibition of melanoma by ultrasound-microbubble-aided drug delivery suggests membrane permeabilization. Cancer Biol Ther (2007) 6:1276-83.

49. Burke CW, Klibanov AL, Sheehan JP, Price RJ. Inhibition of glioma growth by microbubble activation in a subcutaneous model using low duty cycle ultrasound without significant heating. JNeurosurg (2011) 114:1654-61. doi:10.3171/ 2010.11.JNS101201

50. McDannold N, Vykhodtseva N, Hynynen K. Effects of acoustic parameters and ultrasound contrast agent dose on focusedultrasound induced blood-brain barrier disruption. Ultrasound
Med Biol (2008) 20:20. doi:10. 1016/j.ultrasmedbio.2007.11.009

51. Choi JJ, Feshitan JA, Baseri B, Shougang W, Yao-Sheng T, Borden MA, et al. Microbubblesize dependence of focused ultrasound-induced bloodbrain barrier opening in mice in vivo. IEEE Trans Biomed Eng (2010) 57:145-54. doi:10.1109/TBME.2009.2034533

52. Stieger SM, Caskey CF, Adamson RH, Qin S, Curry FR, Wisner ER, et al. Enhancement of vascular permeability with low-frequency contrast-enhanced ultrasound in the chorioallantoic membrane model. Radiology (2007) 243:112-21. doi:10.1148/ radiol.2431060167

53. Delalande A, Kotopoulis S, Postema M, Midoux P, Pichon C. Sonoporation: mechanistic insights and ongoing challenges for gene transfer. Gene (2013) 525(2):191-9. doi:10.1016/j.gene.2013.03.095

54. Sirsi SR, Borden MA. Advances in ultrasound mediated gene therapy using microbubble contrast agents. Theranostics (2012) 2:1208-22. doi:10.7150/thno.4306

55. Dayton PA, Zhao S, Bloch SH, Schumann P, Penrose K, Matsunaga TO, et al. Application of ultrasound to selectively localize nanodroplets for targeted imaging and therapy. Mol Imaging (2006) 5:160-74.

56. Dayton PA, Morgan KE, Klibanov ALS, Brandenburger G, Nightingale KR, Ferrara KW. A preliminary evaluation of the effects of primary and secondary radiation forces on acoustic contrast agents. IEEE Trans Ultrason Ferroelectr Freq Control (1997) 44:1264-77. doi:10.1109/58.656630

57. Dayton P, Klibanov A, Brandenburger G, Ferrara K. Acoustic radiation force in vivo: a mechanism to assist targeting of microbubbles. Ultrasound Med Biol (1999) 25:1195-201. doi:10.1016/S03015629(99)00062-9

58. O'Reilly MA, Hynynen K. Ultrasound enhanced drug delivery to the brain and central nervous system. Int J Hyperthermia (2012) 28:386-96. doi:10.3109/02656736. 2012.666709

59. Hynynen K, McDannold N, Martin H, Jolesz FA, Vykhodtseva N. The threshold for brain damage in rabbits induced by bursts of ultrasound in the presence of an ultrasound contrast agent (optison). Ultrasound Med Biol 
(2003) 29:473-81. doi:10.1016/ S0301-5629(02)00741-X

60. Baseri B, Choi JJ, Deffieux T, Samiotaki G, Tung Y-S, Olumolade $\mathrm{O}$, et al. Activation of signaling pathways following localized delivery of systemically administered neurotrophic factors across the blood-brain barrier using focused ultrasound and microbubbles. Phys Med Biol (2012) 57:N65-81. doi:10.1088/0031-9155/57/7/N65

61. Choi JJ, Feshitan JA, Shougang W, Yao-Sheng T, Baseri B, Borden $\mathrm{MA}$, et al. The dependence of the ultrasound-induced blood-brain barrier opening characteristics on microbubble size in vivo. AIP Conf Proc (2009) 1113:58-62. doi:10. 1063/1.3131471

62. Choi JJ, Small SA, and Konofagou EE. Optimization of blood-brain barrier opening in mice using focused ultrasound. IEEE Ultrasonics Symposium (IEEE Cat. No.06CH37777); 2006 Oct 36; Vancouver, Canada (2006). p. 540-3.

63. Konofagou EE, Choi J, Baseri B, Lee A. Characterization and optimization of trans-blood-brain barrier diffusion in vivo. AIP Conf Proc (2009) 1113:418-22. doi:10.1063/ 1.3131462

64. Konofagou EE, Choi J, Lee A, Baseri B. Molecular imaging through the blood-brain barrier: safety assessment and parameter dependence. Proc IEEE Int Symp Biomed Imaging; 2009 Jun 28 to Jul 1; Boston, MA (2009). p. 771-4. doi:10.1109/ ISBI.2009.5193163

65. Konofagou EE, Tung Y-S, Choi J, Deffieux T, Baseri B, Vlachos F. Ultrasound-induced blood-brain barrier opening. Curr Pharm Biotechnol (2012) 13:1332-45. doi: 10.2174/138920112800624364

66. Tung YS, Marquet F, Teichert T, Ferrera V, Konofagou EE. Feasibility of noninvasive cavitationguided blood-brain barrier opening using focused ultrasound and microbubbles in nonhuman primates. Appl Phys Lett (2011) 98:163704-1-163704-3. doi:10.1063/1.3580763

67. Fite BZ, Liu Y, Kruse DE, Caskey $\mathrm{CF}$, Walton $\mathrm{JH}$, Lai $\mathrm{CY}$, et al. Magnetic resonance thermometry at 7T for real-time monitoring and correction of ultrasound induced mild hyperthermia. PLoS ONE (2012) 7:e35509. doi:10. 1371/journal.pone.0035509

68. Lai C, Kruse DE, Caskey CF, Stephens DN, Sutcliffe PL, Ferrara KW. Noninvasive thermometry assisted by a dual-function ultrasound transducer for mild hyperthermia. IEEE Trans Ultrason Ferroelectr Freq Control (2010) 57:2671-84. doi:10.1109/TUFFC. 2010.1741

69. Roemer RB. Engineering aspects of hyperthermia therapy. Annu Rev Biomed Eng (1999) 1:347-76. doi:10.1146/annurev.bioeng.1.1. 347

70. Rygh CB, Qin SP, Seo JW, Mahakian LM, Zhang H, Adamson $\mathrm{R}$, et al. Longitudinal investigation of permeability and distribution of macromolecules in mouse malignant transformation using PET. Clin Cancer Res (2011) 17:550-9. doi:10.1158/1078-0432. CCR-10-2049

71. Qin S, Seo JW, Zhang H, Qi J, Curry F-RE, Ferrara KW. An imaging-driven model for liposomal stability and circulation. Mol Pharm (2009) 7:12-21. doi:10. 1021/mp900122j

72. Wong AW, Ormsby E, Zhang H, Seo JW, Mahakian LM, Caskey CF, et al. A comparison of image contrast with (64)Cu-labeled long circulating liposomes and (18)F-FDG in a murine model of mammary carcinoma. Am J Nucl Med $\mathrm{Mol}$ Imaging (2013) 3:32-43.

73. Zheng J, Liu J, Dunne M, Jaffray $\mathrm{D}$, Allen C. In vivo performance of a liposomal vascular contrast agent for CT and MR-based image guidance applications. Pharm Res (2007) 24:1193-201. doi:10.1007/ s11095-006-9220-1

74. Huang H, Dunne M, Lo J, Jaffray DA, Allen C. Comparison of computed tomography- and optical image-based assessment of liposome distribution. Mol Imaging (2013) 12:148-60.

75. Kim CK, Park BK, Lee HM, Kim SS, Kim E. MRI techniques for prediction of local tumor progression after high-intensity focused ultrasonic ablation of prostate cancer. AJR Am J Roentgenol (2008) 190:1180-6. doi:10.2214/AJR.07. 2924

76. Kim CK, Park BK, Kim B. Diffusion-weighted MRI at $3 \mathrm{~T}$ for the evaluation of prostate cancer. AJR Am J Roentgenol (2010) 194:1461-9. doi:10.2214/AJR.09. 3654

77. Hynynen K, Damianou C, Darkazanli A, Unger E, Schenck JF. The feasibility of using MRI to monitor and guide noninvasive ultrasound surgery. Ultrasound Med Biol (1993) 19:91-2. doi:10.1016/ 0301-5629(93)90022-G
78. Funaki K, Fukunishi H, Funaki T, Sawada K, Kaji Y, Maruo T. Magnetic resonance-guided focused ultrasound surgery for uterine fibroids: relationship between the therapeutic effects and signal intensity of preexisting T2-weighted magnetic resonance images. Am J Obstet Gynecol (2007) 196:.el-6. doi:10.1016/j.ajog.2006.08.030

79. McDannold NJ, Hynynen K, Wolf D, Wolf G, Jolesz F. MRI evaluation of thermal ablation of tumors with focused ultrasound. J Magn Reson Imaging (1998) 8:91-100. doi:10.1002/jmri.1880080119

80. Punwani S, Emberton M, Walkden $M$, Sohaib A, Freeman A, Ahmed $\mathrm{H}$, et al. Prostatic cancer surveillance following whole-gland high-intensity focused ultrasound: comparison of MRI and prostate-specific antigen for detection of residual or recurrent disease. $\mathrm{Br} J$ Radiol (2012) 85:720-8. doi:10.1259/bjr/ 61380797

81. Tempany CM, Stewart EA, McDannold N, Quade BJ, Jolesz FA, Hynynen K. MR imagingguided focused ultrasound surgery of uterine leiomyomas: a feasibility study. Radiology (2003) 226:897-905. doi:10.1148/radiol.2271020395

82. Chen L, Bouley D, Yuh E, D'Arceuil H, Butts K. Study of focused ultrasound tissue damage using MRI and histology. J Magn Reson Imaging (1999) 10:146-53. doi:10.1002/(SICI) 1522-2586(199908) 10:2<146: :AID-JMRI6>3.3.CO;2-3

83. Jacobs MA, Ouwerkerk R, Kamel I, Bottomley PA, Bluemke DA, Kim HS. Proton, diffusion-weighted imaging, and sodium (23Na) MRI of uterine leiomyomata after MR-guided high-intensity focused ultrasound: a preliminary study. J Magn Reson Imaging (2009) 29:649-56. doi:10.1002/ jmri. 21677

84. Cirillo S, Petracchini M, D’Urso L, Dellamonica $\mathrm{P}$, Illing $\mathrm{R}$, Regge $\mathrm{D}$, et al. Endorectal magnetic resonance imaging and magnetic resonance spectroscopy to monitor the prostate for residual disease or local cancer recurrence after transrectal high-intensity focused ultrasound. BJU Int (2008) 102:452-8. doi:10.1111/j. 1464-410X.2008.07633.x

85. Wu T, Felmlee JP, Greenleaf JF, Riederer SJ, Ehman RL. Assessment of thermal tissue ablation with MR elastography. Magn Reson Med (2001) 45:80-7. doi:10. 1002/1522-2594(200101)45:1<80: :AID-MRM1012>3.0.CO;2-Y

86. Kirkham AP, Emberton $M$, Hoh IM, Illing RO, Freeman AA, Allen C. MR imaging of prostate after treatment with highintensity focused ultrasound. Radiology (2008) 246:833-44. doi:10.1148/radiol.2463062080

87. Rouviere O, Lyonnet D, Raudrant A, Colin-Pangaud C, Chapelon JY, Bouvier R, et al. MRI appearance of prostate following transrectal HIFU ablation of localized cancer. Eur Urol (2001) 40:265-74. doi:10.1159/000049786

88. Ben Cheikh A, Girouin N, RyonTaponnier P, Mege-Lechevallier F, Gelet A, Chapelon JY, et al. MR detection of local prostate cancer recurrence after transrectal high-intensity focused US treatment: preliminary results. $J$ Radiol (2008) 89:571-7. doi:10. 1016/S0221-0363(08)71483-5

89. Delli Castelli D, Dastru W, Terreno E, Cittadino E, Mainini F, Torres E, et al. In vivo MRI multicontrast kinetic analysis of the uptake and intracellular trafficking of paramagnetically labeled liposomes. J Control Release (2010) 144: 271-9. doi:10.1016/j.jconrel.2010. 03.005

90. Howseman AM, Bowtell RW. Functional magnetic resonance imaging: imaging techniques and contrast mechanisms. Philos Trans $R$ Soc Lond $B$ Biol Sci (1999) 354:1179-94. doi:10.1098/rstb.1999.0473

91. Gore JC, Manning HC, Quarles CC, Waddell KW, Yankeelov TE. Magnetic resonance in the era of molecular imaging of cancer. Magn Reson Imaging (2011) 29:587-600. doi:10.1016/j.mri.2011.02.003

92. Parker DL. Applications of NMR imaging in hyperthermia - an evaluation of the potential for localized tissue heating and noninvasive temperature monitoring. IEEE Trans Biomed Eng (1984) 31:161-7. doi:10.1109/TBME.1984.325382

93. Rieke V, Butts Pauly K. MR thermometry. J Magn Reson Imaging (2008) 27:376-90. doi:10.1002/ jmri.21265

94. Parker DL, Smith V, Sheldon P, Crooks LE, Fussell L. Temperature distribution measurements in two-dimensional NMR imaging. Med Phys (1983) 10:321-5. doi:10. $1118 / 1.595307$ 
95. Le Bihan D, Delannoy J, Levin RL. Temperature mapping with MR imaging of molecular diffusion: application to hyperthermia. Radiology (1989) 171:853-7.

96. Young IR, Hand JW, Oatridge A, Prior MV, Forse GR. Further observations on the measurement of tissue $\mathrm{T} 1$ to monitor temperature in vivo by MRI. Magn Reson Med (1994) 31: 342-5. doi:10.1002/mrm. 1910310317

97. Graham SJ, Stanisz GJ, Kecojevic A, Bronskill MJ, Henkelman RM. Analysis of changes in MR properties of tissues after heat treatment. Magn Reson Med (1999) 42:106171. doi:10.1002/(SICI)15222594(199912)42:6<1061::AIDMRM10>3.0.CO;2-T

98. Chen J, Daniel BL, Pauly KB. Investigation of proton density for measuring tissue temperature. J Magn Reson Imaging (2006) 23:430-7. doi:10.1002/jmri.20516

99. Ishihara $Y$, Calderon A, Watanabe H, Okamoto K, Suzuki Y, Kuroda $\mathrm{K}$, et al. Precise and fast temperature mapping using water proton chemical-shift. Magn Reson Med (1995) 34:814-23. doi:10. 1002/mrm.1910340606

100. Galiana G, Branca RT, Jenista ER, Warren WS. Accurate temperature imaging based on intermolecular coherences in magnetic resonance. Science (2008) 322:421-4. doi:10. 1126/science. 1163242

101. Quesson B, de Zwart JA, Moonen CTW. Magnetic resonance temperature imaging for guidance of thermotherapy. J Magn Reson Imaging (2000) 12:525-33. doi: 10.1002/1522-2586(200010)12: 4<525::AID-JMRI3>3.0.CO;2-V

102. Peters RD, Hinks RS, Henkelman RM. Ex vivo tissue-type independence in proton-resonance frequency shift MR thermometry. Magn Reson Med (1998) 40:454-9. doi:10.1002/mrm.1910400316

103. Weidensteiner C, Kerioui N, Quesson B, de Senneville BD, Trillaud $\mathrm{H}$, Moonen CT. Stability of real-time MR temperature mapping in healthy and diseased human liver. J Magn Reson Imaging (2004) 19:438-46. doi:10. 1002/jmri.20019

104. Bankson JA, Stafford RJ, Hazle JD. Partially parallel imaging with phase-sensitive data: increased temporal resolution for magnetic resonance temperature imaging. Magn Reson Med (2005) 53:65865. doi:10.1002/mrm.20378

105. Guo JY, Kholmovski EG, Zhang L, Jeong EK, Parker DL. k-Space inherited parallel acquisition (KIPA): application on dynamic magnetic resonance imaging thermometry. Magn Reson Imaging (2006) 24:903-15. doi:10.1016/j.mri.2006.03.001

106. Kohler MO, Mougenot C, Quesson B, Enholm J, Le Bail B, Laurent $\mathrm{C}$, et al. Volumetric HIFU ablation under 3D guidance of rapid MRI thermometry. Med Phys (2009) 36:3521-35. doi:10.1118/1. 3152112

107. Enholm JK, Kohler MO, Quesson B, Mougenot C, Moonen CTW, Sokka SD. Improved volumetric MR-HIFU ablation by robust binary feedback control. IEEE Trans Biomed Eng (2010) 57:103-13. doi:10.1109/TBME.2009.2034636

108. Ergun AS. Analytical and numerical calculations of optimum design frequency for focused ultrasound therapy and acoustic radiation force. Ultrasonics (2011) 51:786-94. doi:10.1016/j.ultras.2011.03.006

109. Wu F, Wang Z-B, Cao Y-D, Zhou Q, Zhang Y, Xu Z-L, et al. Expression of tumor antigens and heat-shock protein 70 in breast cancer cells after high-intensity focused ultrasound ablation. Ann Surg Oncol (2007) 14:1237-42. doi:10.1245/ s10434-006-9275-6

110. Wu F, Zhou L, Chen WR. Host antitumour immune responses to HIFU ablation. Int $J$ Hyperthermia (2007) 23:165-71. doi:10. 1080/02656730701206638

111. Zhou Q, Zhu X-Q, Zhang J, $\mathrm{Xu}$ Z-L, Lu P, Wu F. Changes in circulating immunosuppressive cytokine levels of cancer patients after high intensity focused ultrasound treatment. Ultrasound Med Biol (2008) 34:81-7. doi:10.1016/j. ultrasmedbio.2007.07.013

112. Lu P, Zhu X-Q, Xu Z-L, Zhou Q, Zhang J, Wu F. Increased infiltration of activated tumor-infiltrating lymphocytes after high intensity focused ultrasound ablation of human breast cancer. Surgery
(2009) 145:286-93. doi:10.1016/j. surg.2008.10.010

113. Xu Z-L, Zhu X-Q, Lu P, Zhou Q, Zhang J, Wu F. Activation of tumor-infiltrating antigen presenting cells by high intensity focused ultrasound ablation of human breast cancer. Ultrasound Med Biol (2009) 35: 50-7. doi:10.1016/j.ultrasmedbio. 2008.08.005

114. Zhang Y, Deng J, Feng J, Wu F. Enhancement of antitumor vaccine in ablated hepatocellular carcinoma by high-intensity focused ultrasound. World J Gas troenterol (2010) 16:3584-91. doi: 10.3748/wjg.v16.i28.3584

115. Deng J, Zhang Y, Feng J, Wu F. Dendritic cells loaded with ultrasound-ablated tumor induce in vivo specific antitumor responses. Ultrasound $\mathrm{Med}$ Bio (2010) 36:441-8. doi:10.1016/j. ultrasmedbio.2009.12.004

116. Higgins JP, Bernstein MB, Hodge JW. Enhancing immune responses to tumor-associated antigens. Cancer Biol Ther (2009) 8:1440-9. doi:10.4161/cbt.8.15.9133

117. Liu F, Hu Z, Qiu L, Hui C, Li C, Zhong P, et al. Boosting high-intensity focused ultrasound-induced anti-tumor immunity using a sparse-scan strategy that can more effectively promote dendritic cell maturation. J Transl Med (2010) 8:7. doi:10.1186/1479-5876-8-7

118. Dalfior D, Delahunt B, Brunelli M, Parisi A, Ficarra V, Novara G, et al. Utility of racemase and other immunomarkers in the detection of adenocarcinoma in prostatic tissue damaged by high intensity focused ultrasound therapy. Pathology (2010) 42:1-5. doi:10. 3109/00313020903434447

119. Zhong-Lin X, Xue-Qiang Z, Pei L, Qiang Z, Jun Z, Feng W. Activation of tumor-infiltrating antigen presenting cells by high intensity focused ultrasound ablation of human breast cancer. Ultrasound Med Biol (2009) 35(1):50-7. doi:10.1016/j.ultrasmedbio. 2008 . 08.005

120. Zhang H, Liu L, Sharma R, Alfieri A, Saha S, Garg M, et al. High intensity focused ultrasound (HIFU)-enhanced autologous in situ vaccination for prostate cancer. Int J Radiat Oncol Biol Phys (2008) 72:S165-6. doi: 10.1016/j.ijrobp.2008.06.516

121. Hu Z, Yang XY, Liu Y, Sankin GN, Pua EC, Morse MA, et al. Investigation of HIFU-induced anti-tumor immunity in a murine tumor model. J Transl Med (2007) 5:34. doi:10.1186/1479-5876-5-34

122. Zerbini A, Pilli M, Fagnoni F, Pelosi G, Pizzi MG, Schivazappa $S$, et al. Increased immunostimulatory activity conferred to antigenpresenting cells by exposure to antigen extract from hepatocellular carcinoma after radiofrequency thermal ablation. J Immunother (2008) 31:271-82. doi:10.1097/ CJI.0b013e318160ff1c

123. ter Haar G, Rivens I, Chen L, Riddler S. High intensity focused ultrasound for the treatment of rat tumours. Phys Med Biol (1991) 36:1495-501. doi:10.1088/ 0031-9155/36/11/009

124. Chen L, ter Haar G, Hill CR, Eccles SA, Box G. Treatment of implanted liver tumors with focused ultrasound. Ultrasound Med Biol (1998) 24:1475-88. doi: 10.1016/S0301-5629(98)00134-3

Conflict of Interest Statement: The authors declare that the research was conducted in the absence of any commercial or financial relationships that could be construed as a potential conflict of interest.

Received: 28 June 2013; accepted: 25 July 2013; published online: 19 August 2013. Citation: Lai C-Y, Fite BZ and Ferrara KW (2013) Ultrasonic enhancement of drug penetration in solid tumors. Front. Oncol. 3:204. doi: 10.3389/fonc.2013.00204

This article was submitted to Frontiers in Pharmacology of Anti-Cancer Drugs, a specialty of Frontiers in Oncology. Copyright (c) 2013 Lai, Fite and Ferrara. This is an open-access article distributed under the terms of the Creative Commons Attribution License (CC BY). The use, distribution or reproduction in other forums is permitted, provided the original author(s) or licensor are credited and that the original publication in this journal is cited, in accordance with accepted academic practice. No use, distribution or reproduction is permitted which does not comply with these terms. 